\title{
Augmentation of histone deacetylase 3 (HDAC3) epigenetic signature at the interface of proinflammation and insulin resistance in patients with type 2 diabetes
}

\author{
Chandrakumar Sathishkumar, Paramasivam Prabu, Mahalingam Balakumar, Raji Lenin, Durai Prabhu,
} Ranjith Mohan Anjana, Viswanathan Mohan and Muthuswamy Balasubramanyam*

\begin{abstract}
Background: A role of proinflammation has been implicated in the pathogenesis of diabetes, but the up-stream regulatory signals and molecular signatures are poorly understood. While histone modifications such as changes in histone deacetylase (HDAC) are emerging as novel epigenetic biomarkers, there is lack of studies to demonstrate their clinical relevance in diabetes. Therefore, we investigated the extent of HDAC machinery and inflammatory signals in peripheral blood mononuclear cells (PBMCs) from patients with type 2 diabetes mellitus (T2DM) compared to control subjects.

Results: HDAC3 activity was significantly $(p<0.05)$ increased in patients with T2DM compared to control subjects. While subtypes of HDACs were differentially expressed at their transcriptional levels in patients with type 2 diabetes, the most prominent observation is the significantly $(p<0.05)$ elevated messenger RNA (mRNA) levels of HDAC3. Expression levels of Sirt1 which represents the class III HDAC were decreased significantly in T2DM $(p<0.05)$. Plasma levels of both TNF- $a$ and IL-6 were significantly higher $(p<0.05)$ in patients with type 2 diabetes compared to control subjects. Among the proinflammatory mediators, the mRNA expression of MCP-1, IL1- $\beta$, NFKB, TLR2, and TLR4 were also significantly $(p<0.05)$ increased in T2DM. Transcriptional levels of DBC1 (deleted in breast cancer 1 , which is a negative regulator of HDAC3) were seen significantly reduced in PBMCs from T2DM. Interestingly, HDAC3 activity/HDAC3 mRNA levels positively correlated to proinflammation, poor glycemic control, and insulin resistance.

Conclusions: Striking message from this study is that while looking for anti-inflammatory strategies and drugs with novel mode of action for T2DM, discovering and designing specific inhibitors targeted to HDAC3 appears promising.
\end{abstract}

Keywords: HDAC3, Inflammation, Insulin resistance, Type 2 diabetes, Epigenetics, Sirt1, Histone modification

\section{Background}

More than 415 million people are estimated to have diabetes worldwide now, and the prevalence of diabetes in India alone is estimated to be 69.2 million, with ever increasing morbidity and mortality [1]. Asian Indians have unique clinical and biochemical abnormalities which makes them more prone to diabetes and premature

\footnotetext{
* Correspondence: balusignal@gmail.com

Department of Cell and Molecular Biology and Dr. Rema Mohan High-Throughput Screening (HTS) Lab, Madras Diabetes Research Foundation and Dr. Mohan's Diabetes Specialties Centre, Gopalapuram, Chennai 600086, India
}

coronary artery diseases [2, 3]. Low-grade chronic inflammation and insulin resistance appear to play a key role in the pathogenesis of diabetes and its major vascular complications $[4,5]$. Serum levels of inflammatory and chemokine markers have not only been strongly associated but also appear to be independent predictors of type 2 diabetes [4-6]. We have demonstrated increased proinflammatory markers and ER stress accompanied by impaired miR-146a in patients with type 2 diabetes that showed association with several metabolic risk factors $[7,8]$. Although proinflammation has been linked to 
insulin resistance and development of type 2 diabetes, the underlying and up-stream molecular and cellular mechanisms remain enigmatic.

Interactions of environmental factors with genetic and epigenetic variants are likely to play an important role in the pathogenesis of type 2 diabetes [9]. Aberrant epigenetic modifications such as DNA methylation, histone modification, and microRNA alterations are well recognized drivers for the cancer phenotype, but the accumulating evidence also imply their role in the etiology of diabetes and cardiovascular diseases. In recent years, histone deacetylases (HDACs) have received increasing attention in the context of several disease states including type 2 diabetes [10] and they are considered as emerging druggable targets. Based upon their yeast sequence homology, HDACs are classified into four groups namely, class I (HDAC1, 2, 3, and 8), class II (HDAC4, 5, 6, 7, 9, and 10), class III (sirtuins 1-7), and class IV (HDAC11). As HDAC modulates the acetylation status of histone and other important nonhistone cellular proteins, they have been recognized as potential therapeutic targets for a broad range of human disorders [11] and inhibition of HDAC has been suggested as a new therapeutic intervention of potential importance in type 2 diabetes [12].

Although clinical evidence on the impact of different classes of HDACs on metabolic risks are only emerging, works on animal and cell models suggest HDAC inhibition as a potential therapeutic avenue. With special reference to the skeletal muscle and adipose tissue, class I selective HDAC inhibition has been shown to increase expression of several key mitochondria-related transcription factors, as well as the levels of multiple genes involved in glucose and lipid metabolism [13]. Class I HDAC inhibitor MS-275 prevents $\beta$-cell death elicited by cytokines and prevented from apoptosis induced by saturated free fatty acid palmitate treatment associated with reduced endoplasmic stress marker $\mathrm{CHOP}$ and ATF3 [14]. On the other hand, sirtuin1 (Sirt1, a class III HDAC) which is a well-known metabolic regulator of glucose homeostasis and insulin resistance-associated inflammation is reduced in diabetes, and enhanced activity of sirt1 has been shown to be protective against diabetes [15]. Since different HDACs have distinct role in various metabolic pathways, signaling, and functions, the idea of pan HDAC inhibition may not work effectively with minimal/zero side effects. Therefore, elucidating the individual HDAC status, function, and its clinical relevance to metabolic pathways is the need of the day. While Asian Indians are more prone to develop type 2 diabetes and other vascular complications, there is lack of data on epigenetic signatures in the context of clinical diabetes setting. Therefore, in this study, we used peripheral blood mononuclear cells (PBMCs) as a surrogate cell model to delineate the activity and transcriptional levels of different HDACs and to correlate their association with glycemia, proinflammation, and insulin resistance in patients with type 2 diabetes.

\section{Methods \\ Study design and methods}

Study subjects (both males and females) were recruited from the on-going epidemiological studies at the Madras Diabetes Research Foundation and Dr. Mohan's Diabetes Specialties Centre, Chennai, India. With a pilot study and considering the primary outcome variables (HDAC3 activity), the required sample size for the study was calculated to be $n=22$ in each arm in order to have $80 \%$ statistical power with an alpha error of $5 \%$. Therefore, the study comprised of two groups $(n=25$ each) viz., subjects with normal glucose tolerance (NGT) and patients with type 2 diabetes mellitus (T2DM). Subjects were characterized either as NGT or T2DM according to WHO criteria. Of the diabetic patients, $92 \%$ of them were on oral hypoglycemic agents (OHA) and $8 \%$ were on insulin in addition to OHA. The study has been carried out in accordance with the guidelines of Declaration of Helsinki and was approved by the Institutional Ethics Committee of the Madras Diabetes Research Foundation, and informed written consent has been obtained from all the study subjects.

\section{Anthropometric measurements}

Anthropometric measurements including height, weight, and waist circumstance were obtained using standardized techniques. Height was noted with a tape measured to the nearest centimeter. Weight was measured with traditional spring balance that was kept on a firm horizontal surface. The body mass index (BMI) was calculated using the formula, weight $(\mathrm{kg}) /$ height $(\mathrm{m})^{2}$. Waist circumference was measured using a non-stretchable fiber measuring tape. Blood pressure was recorded from the right arm of study subjects when they were relaxed and in sitting position to the nearest $2 \mathrm{mmHg}$ with a mercury sphygmomanometer (Diamond Deluxe BP apparatus, Pune, India). Two reading were taken $5 \mathrm{~min}$ apart, and the mean of the two was taken as the blood pressure.

\section{Biochemical investigations}

Fasting plasma glucose (glucose oxidase-peroxidase method), serum cholesterol (cholesterol oxidaseperoxidase-amidopyrine method), serum triglycerides (glycerol phosphate oxidase-peroxidase-amidopyrine method) and HDL cholesterol (direct methodpolyethylene glycol-pretreated enzymes) were measured using Hitachi-912 Autoanalyser (Hitachi, Mannheim, Germany). The intra- and inter-assay coefficient of variation for the biochemical assays were 
$<5 \%$. Low-density lipoprotein (LDL) cholesterol was calculated using the Friedewald formula [16]. Glycated hemoglobin (HbAlc) was estimated by highpressure liquid chromatography using the variant analyzer (Bio-Rad, Hercules, Calif., USA). Serum insulin was estimated using enzyme-linked immunosorbent assay (Calbiotech, CA). The intra-assay and the inter-assay coefficients of variation for insulin assay was $<10 \%$. Insulin resistance was calculated using the homeostasis assessment model (HOMA-IR) using the formula: fasting insulin $(\mu \mathrm{IU} / \mathrm{mL})$ *fasting glucose $(\mathrm{mmol} / \mathrm{L}) / 22.5$.

\section{Blood collection and PBMC preparation}

About 8 to $10 \mathrm{~mL}$ of fasting $(8-12 \mathrm{~h})$, venous blood was collected in the anticoagulant (ACD) vacutainer from the study group subjects according to the standard procedures. All fresh blood collected was processed immediately within $2 \mathrm{~h}$ from the time of collection. Plasma was separated from the whole blood by centrifuging tubes at $3000 \mathrm{rpm}$ for $20 \mathrm{~min}$ at room temperature and stored at $-80{ }^{\circ} \mathrm{C}$ until analyzed for cytokines. Blood was also processed for $\mathrm{PBMC}$ isolation using Histopaque1077 (Sigma-Aldrich) according to the standard protocol by overlaying the blood on density gradient solution and centrifuged at $1500-1800 \mathrm{rpm}$ for $30 \mathrm{~min}$. The Buffy coat layer containing the peripheral blood mononuclear cells (PBMCs) was collected, washed thrice with phosphate-buffered saline (PBS, pH 7.2-7.4), and used immediately and separately for nuclear protein extraction and total RNA isolation.

\section{Fractionation of nuclear extract}

Nuclear protein was extracted from freshly isolated PBMCs using ProteoJET Cytoplasmic and Nulcear Protein Extraction Kit (Fermentas, Canada). Briefly, $8 \times 10^{6}$ PBMCs were suspended in $300 \mu \mathrm{L}$ of cell lysis buffer, vortexed for $10 \mathrm{~s}$, and incubated for $10 \mathrm{~min}$ at $4{ }^{\circ} \mathrm{C}$. After the first round of centrifugation at $500 \times g$ for $7 \mathrm{~min}$, the supernatants were separated as cytoplasmic fraction and the pellet was processed as nuclear extract. The pellet was rinsed twice with nuclei washing buffer, resuspended in nuclei storage buffer, and subsequently treated with nuclei lysis reagent. After an incubation for $20 \mathrm{~min}$ on ice with repetitive vortexing done every $3 \mathrm{~min}$, the resulting nuclear extract were centrifuged at $20,000 \times g$ for $5 \mathrm{~min}$ at $4{ }^{\circ} \mathrm{C}$; supernatants were collected as nuclear fractions and frozen at $-80{ }^{\circ} \mathrm{C}$ for later analysis.

\section{Global HDAC/specific HDAC3 activity assay}

Global HDAC activity in PBMC nuclear extract was assessed using a Fluorometric HDAC Activity Assay Kit (Biovision, CA). All PBMC samples were incubated with
HDAC substrate (Boc-Lys(Ac)-AMC). Deacetylation of substrate sensitizes substrate, and further addition of lysine developer produces a fluorophore, which was captured as the fluorescence read-out using a plate reader with Ex. $=350-380 \mathrm{~nm}$ and Em. $=440-460 \mathrm{~nm}$ settings. The standard curve was prepared as per recommended dilution range by the kit protocol. The absolute HDAC activity was calculated based on the slope determined by the standard deacetylated curve and expressed as $\mu \mathrm{M} /$ $\mathrm{mL}$. Positive and negative controls were carried out during every experiment. Specific $H D A C 3$ activity was assessed using the $H D A C 3$ activity assay kit (Biovision, $\mathrm{CA}$ ) as per the manufactures' protocol. Absolute $H D A C 3$ activity was calculated based on the slope determined by the standard deacetylated curve and expressed as pmol/ $\mathrm{min} / \mathrm{mL}$.

\section{Total RNA isolation and CDNA preparation}

Transcriptional levels of specific gene alterations in PBMCs were studied in a subset $(n=14$ each) of the NGT and T2DM groups. Total RNA was isolated using TRIzol reagent (Invitrogen). RNA quantity and quality were assessed by NanoDrop 2000 (Thermo scientific) instrument. Then, $1 \mu \mathrm{g}$ of total RNA was taken for the firststrand complementary DNA (cDNA) synthesis reaction. Briefly, RNA was adjusted with nuclease-free water and mixed with cDNA synthesis master mix (NEB) containing 100 units of M-MuLV reverse transcriptase enzyme and $2 \mathrm{X}$ buffer, $40 \mu \mathrm{M}$ oligo $\mathrm{dT}$ and random hexamer primer mix, 20 units of RNase inhibitor, and $10 \mathrm{mM}$ dNTPs solution mix. The resultant samples were incubated at $42{ }^{\circ} \mathrm{C}$ for $60 \mathrm{~min}$ for first-strand cDNA synthesis followed by $5 \mathrm{~min}$ at $95{ }^{\circ} \mathrm{C}$ for enzyme deactivation. cDNA reaction negative control without reverse transcriptase enzyme $(-\mathrm{RT})$ was performed with the experiment.

\section{Quantitative real time PCR}

The relative expression of the messenger RNA (mRNA) was analyzed by preparing reaction mixer with Power SYBR Green PCR Master Mix (2X) (Applied Biosystems) and gene specific primers with diluted $\mathrm{CDNA}$ and final volume made up to $20 \mu \mathrm{L}$ with nuclease-free water. Quantification and analysis were carried out in $\mathrm{ABI}$ prism 7000 (Applied Biosystems) real time PCR. The target gene expression was normalized to the house keeping gene $\beta$-actin, and relative expression was determined using Delta Delta Ct (DDCt) method. Nontemplate control (NTC) was performed for each reaction assay plates.

\section{Plasma TNF- $\alpha$ and IL-6 measurements (ELISA)}

Plasma tumor necrosis factor- $\alpha$ (TNF- $\alpha$ ) and interleukin- 6 (IL-6) levels were measured by quantitative sandwich enzyme-linked immunosorbent assay (ELISA) (eBioscience, CA, USA). In brief, capture antibody specific for TNF- $\alpha$ or 
IL- 6 was coated in the microplate a day prior to the experiment, sealed, and incubated overnight at $4{ }^{\circ} \mathrm{C}$. The next day, plate was washed with washing buffer and standards or samples added to the appropriate wells. After incubation at room temperature for $2 \mathrm{~h}$, TNF- $\alpha$ or IL- 6 bound to the capture antibody and unbound was washed in the next step. Then, detection antibody followed by Avidin-HRP was added, incubated, and washed away. Finally, the color was developed after the addition of substrate solution. The reaction was stopped by stop solution and read at 450 and $570 \mathrm{~nm}$. The values were expressed as $\mathrm{pg} / \mathrm{mL}$ units. The intra- and inter-assay coefficients of variation were $<10 \%$.

\section{Statistical analysis}

All data are represented as mean \pm standard error mean (SEM) until otherwise mentioned as standard deviation (SD). Comparison between groups were performed using unpaired student $t$ test and one-way ANOVA with $p<0.05$ as the criterion for significance. Pearson correlation was done between variables and the risk factors. All analysis was done using IBM SPSS statistics package 20 and Graphpad prism (version 6).

\section{Results}

\section{Clinical and biochemical characterization}

Table 1 illustrates clinical and biochemical parameters of the study subjects. There were no significant differences in age, BMI, and waist circumferences among study groups. Systolic blood pressure was significantly higher in the T2DM patients compared to control subjects. Fasting plasma glucose $(p<0.001)$, HbAlc $(p<0.001)$, and HOMA-IR $(p<0.001)$ were significantly increased in the
T2DM patients. Lipid profiles did not differ among the study subjects. This clinical characterization of our study subjects signifies that to major extent, both hyperglycemia and insulin resistance were the main clinical phenotype in type 2 diabetes compared to control subjects.

\section{Altered HDAC epigenetic signatures in patients with T2DM}

The global histone deacetylase (HDAC) activity was significantly impaired $(p<0.001)$ in patients with type 2 diabetes compared to control subjects (Fig. 1). Then, we have also analyzed the individual subtypes of HDAC mRNA expression patterns (Fig. 2) from PBMCs in patients with type 2 diabetes compared to control subjects. Among the different subtypes of HDACs, HDAC3 mRNA expression was significantly $(p<0.05)$ elevated and HDAC2 mRNA seen decreased $(p<0.05)$ in T2DM. Both HDAC1 and HDAC4 also showed altered levels (albeit not statistically significant) in T2DM at transcriptional levels. Sirt1 which represents the class III HDACs was decreased significantly $(p<0.05)$ in T2DM. As the highly significant HDAC3 mRNA expression was the prominent finding in our study in PBMCs from patients with type 2 diabetes, we then analyzed the specific HDAC3 activity in the study samples. Most strikingly, consistent with HDAC3 mRNA expression, PBMCs from patients with T2DM showed highly significant $(p<0.001)$ elevated levels of HDAC3 activity (Fig. 3a). Among the patients with type 2 diabetes, only two were on insulin in addition to OHAs. Analysis of data on HDAC3 activity, HDAC3 mRNA, and global HDAC activity showed that there were no differences in these

Table 1 Clinical and biochemical characteristics of the study subjects

\begin{tabular}{|c|c|c|c|}
\hline Parameter & Normal glucose tolerance (NGT) $(n=25)$ & Type 2 diabetes mellitus (T2DM) patients $(n=25)$ & $p$ value $^{*}$ \\
\hline Age (years) & $45.2 \pm 9$ & $45.0 \pm 9$ & 0.928 \\
\hline Gender-male (female) & $14(11)$ & $16(9)$ & - \\
\hline Body mass index $\left(\mathrm{kg} / \mathrm{m}^{2}\right)$ & $25.5 \pm 3.5$ & $26.6 \pm 4.3$ & 0.318 \\
\hline Waist circumference $(\mathrm{cm})$ & $94 \pm 7$ & $93 \pm 11$ & 0.964 \\
\hline Fasting plasma glucose (mg/dl) & $94 \pm 11$ & $189 \pm 46$ & $<0.001^{*}$ \\
\hline Glycated hemoglobin-HbA1c (\%) & $5.9 \pm 0.4$ & $9.2 \pm 1.7$ & $<0.001^{*}$ \\
\hline HOMA-IR & $2.09 \pm 1$ & $4.4 \pm 1.6$ & $<0.001^{*}$ \\
\hline Systolic blood pressure (mmHg) & $123 \pm 10$ & $135 \pm 21$ & $<0.05^{*}$ \\
\hline Diastolic blood pressure (mmHg) & $79 \pm 8$ & $81 \pm 11$ & 0.426 \\
\hline Total cholesterol (mg/dl) & $171 \pm 32$ & $170 \pm 48$ & 0.953 \\
\hline Serum triglycerides $(\mathrm{mg} / \mathrm{dl})$ & $122 \pm 52$ & $140 \pm 69$ & 0.285 \\
\hline HDL cholesterol (mg/dl) & $41 \pm 9$ & $40 \pm 8$ & 0.389 \\
\hline LDL cholesterol (mg/dl) & $108 \pm 31$ & $103 \pm 37$ & 0.624 \\
\hline
\end{tabular}

Data represented as mean \pm standard deviation (SD). Italic values are to indicate the statistical significance

${ }^{*} p$ value for comparison between NGT and T2DM individuals 


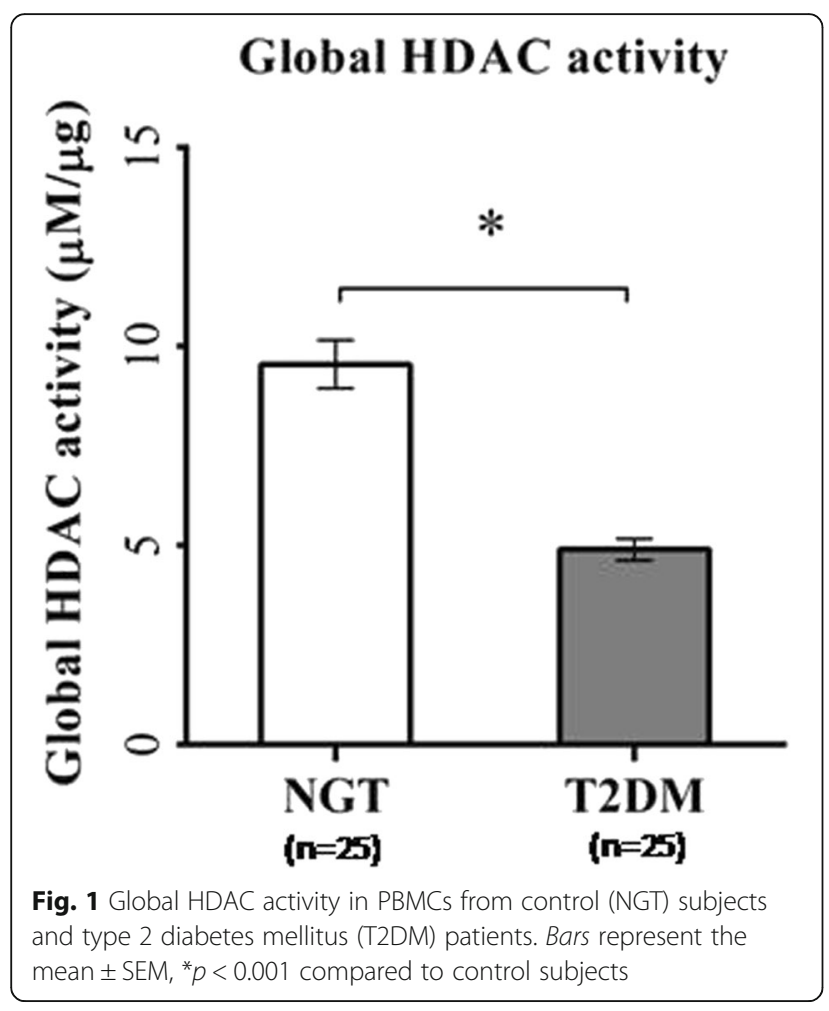

parameters in T2DM with OHA alone compared to T2DM with OHA + insulin. When analyzed for gender, HDAC3 activity was increased $(p<0.001)$ to the extent of 2.7 -fold in females (Fig. 3c) while it was 2.1 -fold increased $(p<0.001)$ in male patients with T2DM (Fig. 3b) compared to their counterpart control subjects.

Systemic and cellular levels of proinflammatory markers Plasma levels of both TNF- $\alpha(p<0.001)$ and IL-6 ( $p=$ 0.002 ) were significantly higher in patients with type 2 diabetes compared to control subjects (Fig. 4a, b). Among the proinflammatory mediators, the mRNA expression of monocyte chemoattractant protein 1 (MCP-1), IL1- $\beta$, nuclear factor kappa-B (NFkB), Toll-like receptor 2 (TLR2), and Toll-like receptor 4 (TLR4) were significantly $(p<$ 0.05 ) increased in T2DM (Fig. 5) while both the expression levels of TNF- $\alpha$ and IL- 6 showed an increasing trend but not statistically significant. Interestingly, SOCS3 mRNA expression was significantly elevated $(p<0.05)$, and DBC1 mRNA expression was significantly $(p<0.05)$ decreased in PBMCs from T2DM patients (Fig. 5).

\section{HDAC3 activity/HDAC3 mRNA correlated with clinical, metabolic, and molecular risk factors}

Pearson correlation analysis was done to check the relationship among HDAC3 activity/HDAC3 mRNA and other risk variables (Table 2). HDAC3 activity was significantly and positively correlated with fasting plasma glucose $(r=0.611, p<0.001)$, HbA1c $(r=0.474, p=0.001)$, and insulin resistance HOMA-IR $(r=0.526, p<0.001)$ $H D A C 3$ activity also showed positive correlation with circulating TNF- $\alpha(r=0.534, p<0.001)$ and IL-6 $(r=0.617$, $p<0.001)$. These associations are similar in both males and females. HDAC3 mRNA levels were also more or less similarly correlated to the above clinical and biochemical parameters. Pearson correlation analysis also revealed a strong positive correlation between the $H D A C 3$ activity and mRNA level of HDAC3 gene expression, various proinflammatory markers (MCP-1, NFkB, IL-1 $\beta$, SOCS3, TLR2, TLR4), and negative association with Sirt1 and deleted in breast cancer 1 (DBC-1) transcriptional levels (Table 2). However, HDAC3 mRNA levels showed positive correlation only with transcriptional levels of MCP-1 and SOCS3. Logistic regression analysis using type 2 diabetes as dependent variable showed HDAC3 activity or HDAC3 mRNA was associated significantly $(p=0.005)$ with T2DM, and this statistical significance was persisted even after adjusted for confounding factors like age and BMI. Interestingly, this association was lost when adjusted for insulin resistance, implying that the association between HDAC3 and T2DM could be closely linked to insulin resistance state.

\section{Discussion}

While there is a great demand in looking for new drug targets and development of novel therapeutic measures (with different mode of actions) for type 2 diabetes, the present study assumes significance for the following reasons. Firstly, this clinically relevant study demonstrated an association of elevated HDAC3 activity and HDAC3 mRNA expression in PBMCs from patients with T2DM. Secondly, increased HDAC3 activity/HDAC3 mRNA level was positively correlated to all the inflammatory markers profiled, poor glycemic control, and insulin resistance. Thirdly, HDAC3 activity exhibited a negative association with transcriptional levels of Sirt1, suggesting an imbalance of HDAC3/Sirt1 circuit. Finally, the transcriptional level of DCB1 (which supposed to negatively regulate HDAC3) was significantly decreased in patients with T2DM.

Tracing molecular events through different layers of biological information, including histone modifications and physiological data, is required for solving the puzzle of the etiology of type 2 diabetes and other metabolic disorders. Several animal and cell model studies have emphasized that class I HDAC inhibition could promote the mitochondrial biogenesis, induce oxidative metabolism, and beneficially alter glucose and lipid metabolism [13, 17]. Studies by Larsen et al. [18] and Lundh et al. [19] have revealed that HDAC inhibition prevents cytokine-induced $\beta$ cell apoptosis 
a

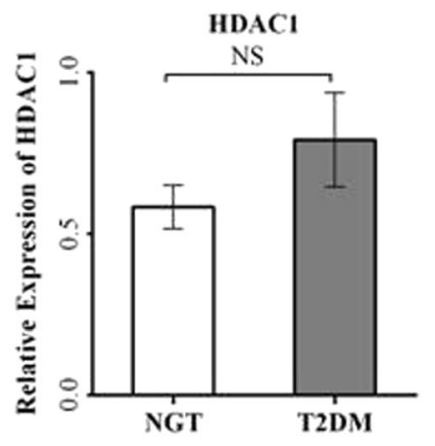

C

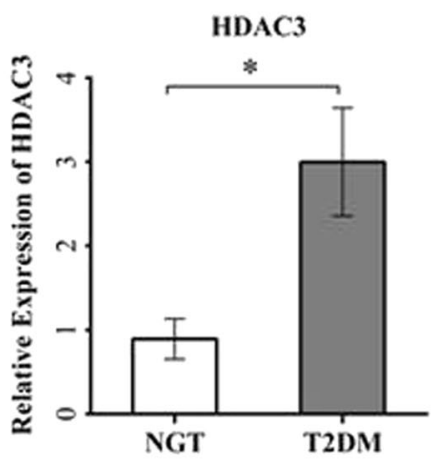

e

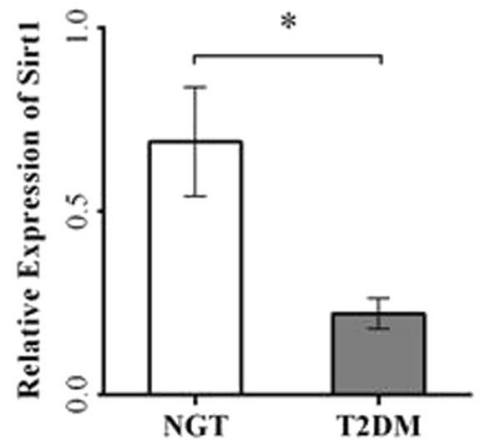

b

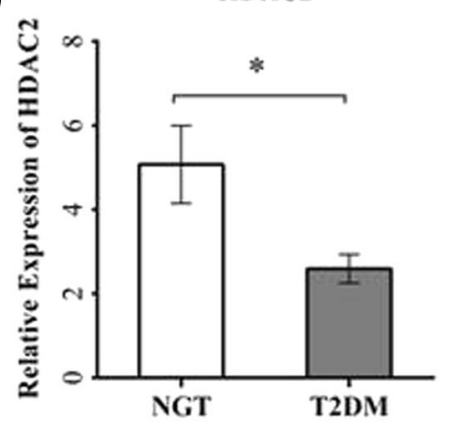

d

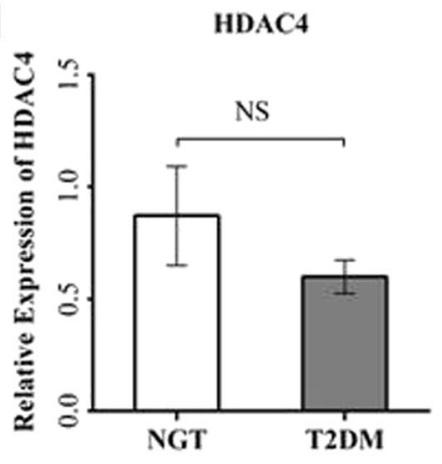

Fig. 2 Real-time quantitative RT-PCR analysis of mRNA expression levels, viz., HDAC1 (a), HDAC2 (b), HDAC3 (c), HDAC4 (d), and Sirt1 (e) in PBMCs from control subjects and type 2 diabetes patients ( $n=14$ each). Bars represent the mean \pm SEM, ${ }^{*} p$ value $<0.05$ compared to control subjects, NS not significant

and impaired $\beta$ cell function associated with a downregulation of $\mathrm{NFkB}$ transactivating activity. Genetic silencing or pharmacological inhibition of HDAC isoforms 1, 2, and 3 have been shown to increase MKP-1 acetylation and decrease LPS-induced MAPKp38 phosphorylation and TNF- $\alpha$, IL1- $\beta$, NOS2, and nitrate synthesis [20]. In our study, we observed increased HDAC1 mRNA expression (albeit not statistically significant) in patients with type 2 diabetes. In patients with type 2 diabetes, we also observed significantly decreased HDAC2 mRNA expression in PBMCs. Earlier, it has been shown that HDAC2 expression was reduced in endothelial cells when exposed to oxLDL, and HDAC2 also decreased in the atherosclerotic lesions of human coronary arteries [21]. While the functional significance of alterations in HDAC1 and HDAC2 needs to be clarified in metabolic disorders, our study unraveled a consistent increase in both HDAC3 activity and HDAC3 transcriptional levels in PBMCs from patients with type 2 diabetes. As PBMCs serve as a potentially accessible surrogate cell model to study the pathogenesis of diabetes and its complications [22], our study using PBMCs as a proxy for demonstrating the epigenetic alterations with special reference to HDAC3 and inflammation is significantly important as these cells infiltrate peripheral organs/tissues and culminate in the etiology of type 2 diabetes. 

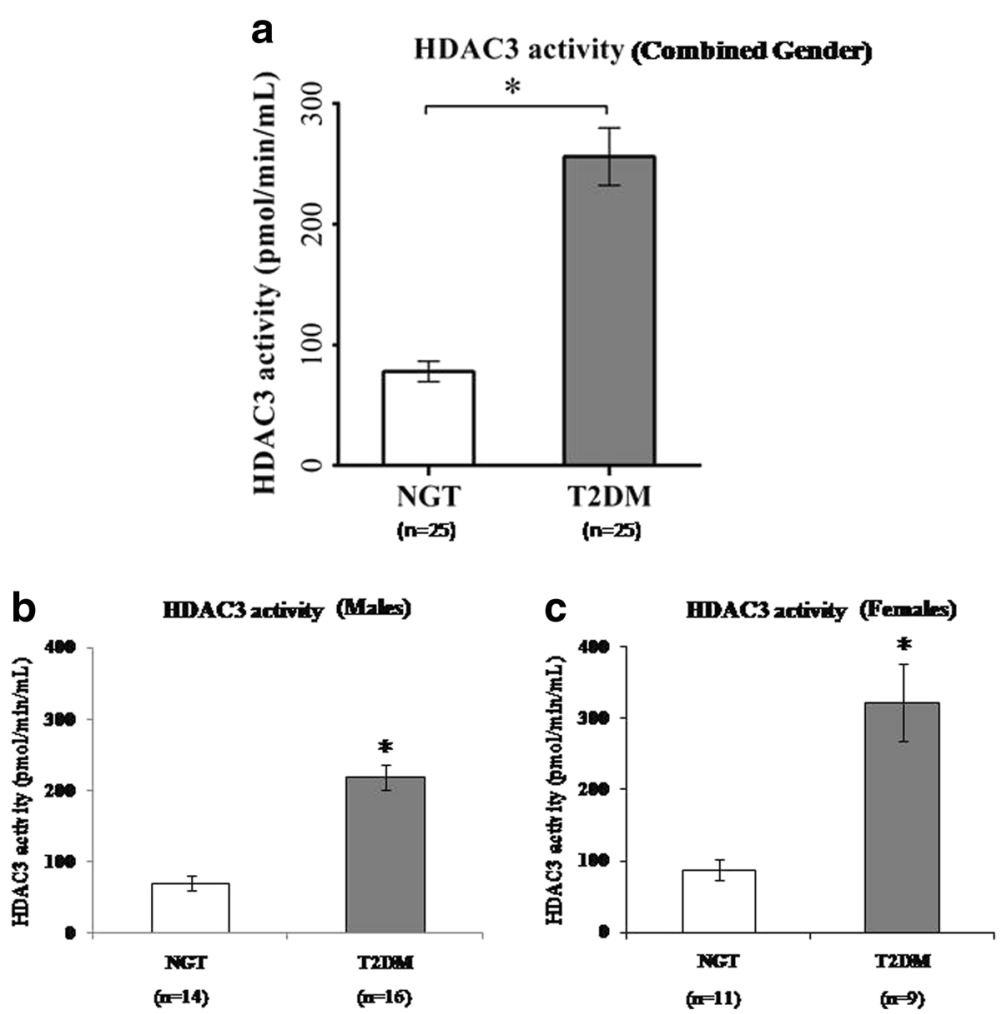

Fig. 3 HDAC3 activity in PBMCs from control (NGT) subjects and type 2 diabetes mellitus (T2DM) patients—combined gender (a), males (b), and females (c). HDAC3 activity expressed in pmol $/ \mathrm{min} / \mathrm{mL}$. Bars represent the mean $\pm \mathrm{SEM},{ }^{*} p<0.001$ compared to control subjects

In our study, $H D A C 3$ activity is increased several folds in the PBMCs from patients with type 2 diabetes compared to control subjects and it showed strong positive correlation with systemic TNF- $\alpha$ and IL-6; mRNA expressions of MCP-1, SCOS3, and HDAC3; and fasting glucose, HbA1c, and insulin resistance (HOMA-IR), while exhibited a negative association with Sirt1. The correlation of HDAC3 mRNA levels with various clinical and molecular parameters observed in our study also implies that this could have important implications for HDAC3's role as a co-factor in many different protein complexes beyond its deacetylase activity. Among the proinflammatory markers, the mRNA expression of MCP-1, NFKB, TLR2, TLR4, and IL1- $\beta$ were significantly increased in T2DM while both the expression levels of TNF- $\alpha$ and IL- 6 showed an increasing trend. Interestingly, SOCS3 mRNA expression was significantly elevated in T2DM patients, and this feedback regulation might have mirrored the extent of mRNA expression of both TNF- $\alpha$ and IL- 6 seen in our study. In fact, accumulating literature favors inhibition of HDAC3 as a potential strategy for developing novel diabetes therapeutics $[17,23]$. Using an integrated genomic approach, Chen et al. [24] found that HDAC3 deficient macrophages were not able to activate almost half of the inflammatory gene expression program when they are stimulated with LPS and concluded that $H D A C 3$ is required for the activation of innate immunity. High expression of HDAC3 in the liver has been shown to contribute to high-fat dietinduced metabolic syndrome by suppressing the PPAR- $\gamma$ and LXR- $\alpha$-pathways in rats [25]. Interestingly, conditional deletion of HDAC3 in osteoprogenitor cells has been shown to attenuate high-fat diet-induced insulin resistance, hepatic steatosis, and metabolic syndrome [26]. While HDAC3 was the sole HDAC isoform upregulated in ruptured lesions of atherosclerosis, HDAC3 deletion has been shown to shift plaque macrophages to an anti-inflammatory phenotype and reduce lipid accumulation [27]. Interestingly, three single nucleotide variants of the HDAC3 gene were shown associated with type 2 diabetes mellitus in a Chinese population [28]. Very recently using a selective HDAC3 inhibitor (BRD3308), Lundh et al. [29] have demonstrated reduction in hyperglycemia and increase in insulin secretion in a rat model of type 2 diabetes. It has been expected that HDAC inhibitors can elicit transgenerational effects, via cross-talk between different epigenetic mechanisms, to have an impact on disease phenotypes in a beneficial manner. Indeed, Jia et al. [30] have demonstrated that selective HDAC inhibition (targeting HDAC1 and 3) imparted beneficial transgenerational effects in Huntington's disease mice via altered DNA and histone methylation. 


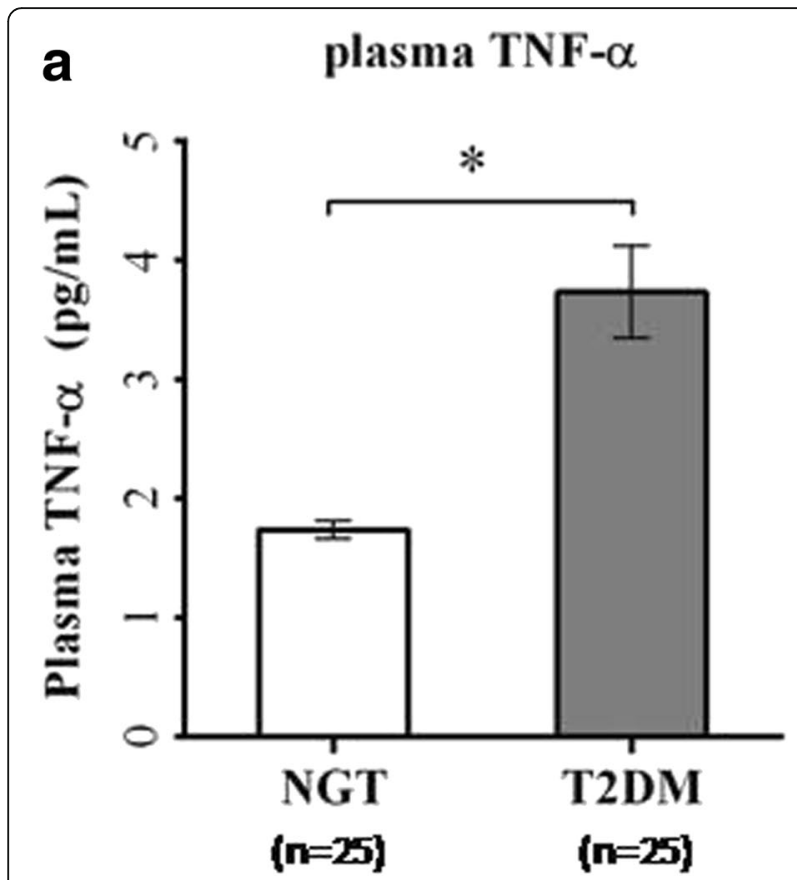

b plasma IL-6

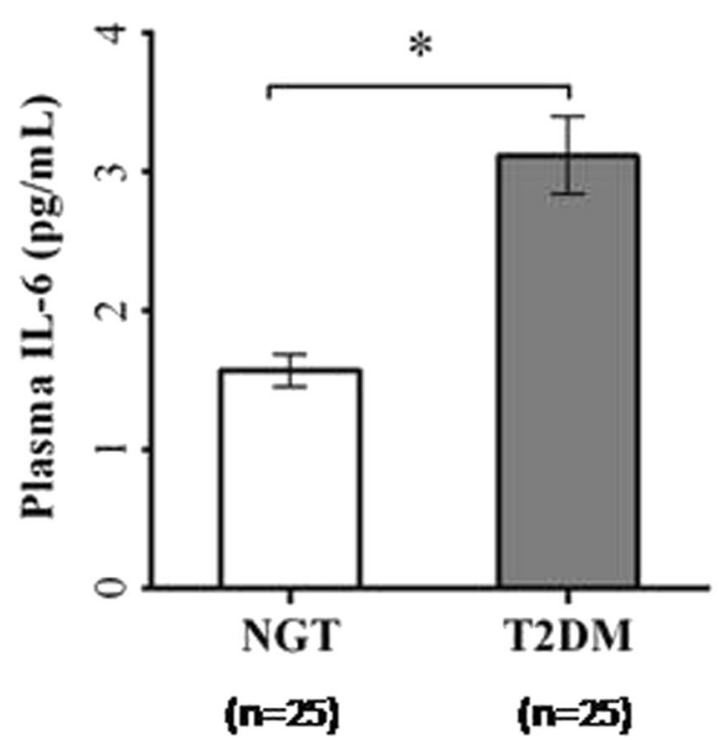

Fig. 4 ELISA of plasma levels of TNF-a (a) and IL-6 (b) from control subjects and patients with type 2 diabetes. Bars represent the mean $\pm \mathrm{SEM},{ }^{*} p<0.001$ compared to control subjects

Consistent with the protective role of Sirt1 (class III HDAC) demonstrated in the literature [31-33], Sirt1 mRNA levels were significantly decreased in PBMCs from patients with type 2 diabetes. Sirt1 protects $\beta$ cells from cytokine-mediated cytotoxicity by altering $\mathrm{NO}$ production and iNOS expression by inhibition of NFKB through P53 pathway [34]. Reduction of Sirt1 has been shown to cause macrophage recruitment and infiltration into the adipose tissue [35-37]. Since Sirt1 is a class III HDAC and it plays a beneficial role in glucose/lipid homeostasis and energy expenditure, non-specific inhibition of all HDACs would have drastic consequences. Another interesting observation in our study is that mRNA levels of DBC1 (deleted in breast cancer 1) were significantly reduced in PBMCs from patients with type 2 diabetes compared to control subjects. DBC1 serves as an endogenous inhibitor HDAC3 [38], and it plays a crucial physiological role as a modulator of epigenetics and metabolic function. In an earlier study, DBC1 knockout mice showed increased expression of PEPCK and gluconeogenesis, whereas over expression DBC1 reduced the PEPCK expression [39]. As we saw a negative correlation between HDAC3 activity and mRNA levels of DBC1 in our study, it appears that the regulatory circuit of endogenous control of HDAC3 could be somehow lost in patients with type 2 diabetes and this needs to be studied in-depth in future investigations.

It is possible that HDACs could negatively regulate certain miRNAs and thereby mediate proinflammation. Recently, increased HDAC3 and TNF $\alpha$ and decreased miRNA-130a expression has been observed in PBMCs from patients with spinal cord injuries [40]. We observed an impairment of miR-146a linked with insulin resistance and inflammation in patients with type 2 diabetes [7]. Interestingly, HDAC inhibitors have been shown to increase miR-146a expression and negatively regulate interleukin- $1 \beta$ signaling in osteoarthritis [41]. These studies emphasize HDAC3/ miRNA axis as a novel regulator of inflammation in type 2 diabetes which should be exploited for novel therapeutic measures.

Having seen the HDAC alterations in the clinical setting of diabetes, it would be interesting to probe and understand whether HDAC regulation by endogenous mediators is also altered in type 2 diabetes. Butyrate is endogenously made in the human body by anaerobic bacterial fermentation of carbohydrates (derived from dietary fiber) in the colon and it has been shown as an inhibitor of HDACs with antiinflammatory activity [42-44]. High-fat diet has been shown to reduce the formation of butyrate [45], and administration of butyrate to diabetic rats reduced insulin resistance and improved glucose tolerance [46, 47]. Chang et al. [48] have also shown that the microbial metabolite butyrate regulates intestinal macrophage function via histone deacetylase inhibition. More importantly from several studies, it has been now realized that butyrate-producing bacterial strain concentrations were lower in patients with type 2 diabetes [49-51]. Therefore, it appears that 


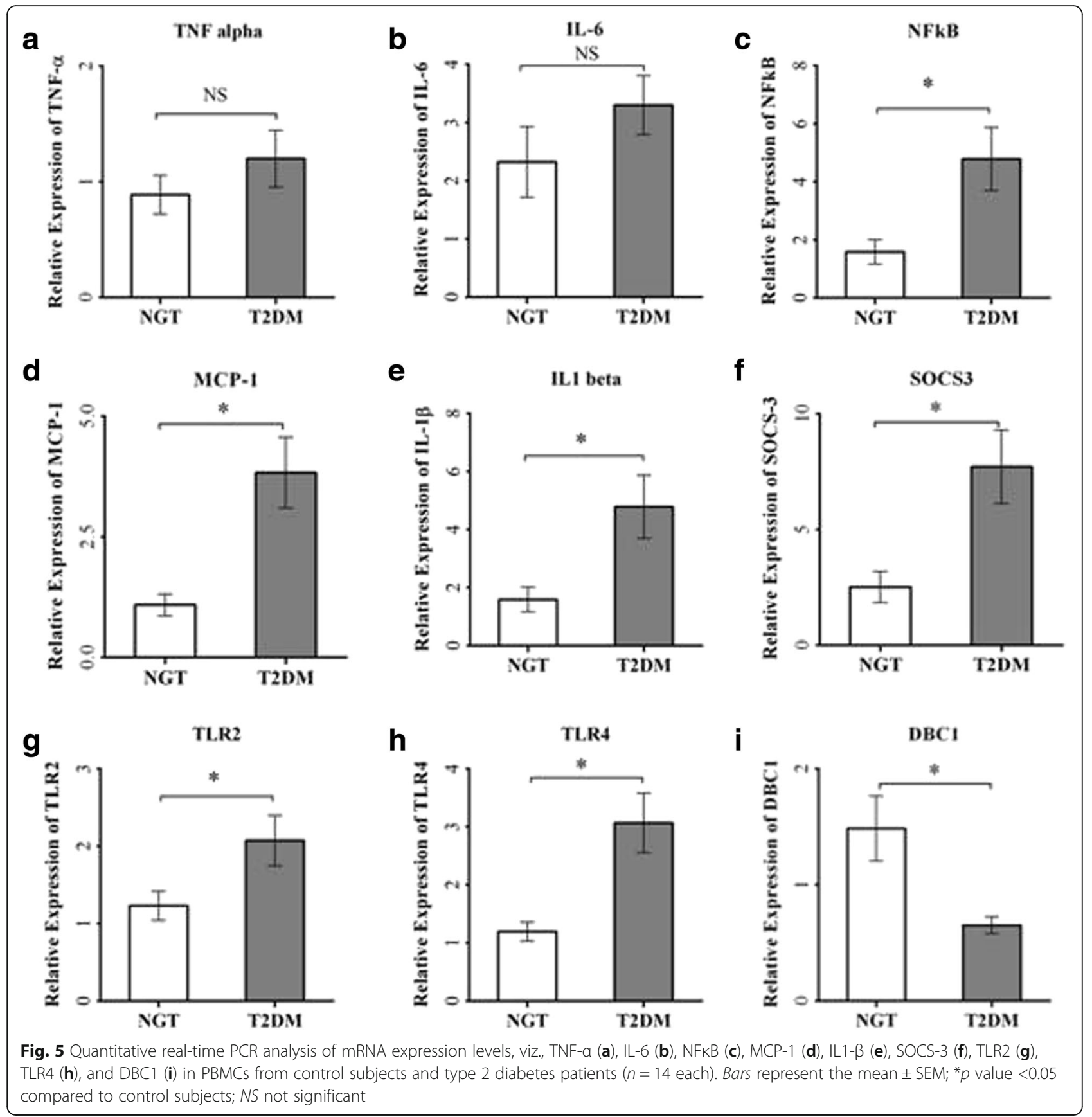

dietary interventions influencing microbial composition and thereby beneficially altering endogenous butyrate levels and/or free fatty acid receptors (FFARs) may be considered as an option in the prevention and treatment of type 2 diabetes and other metabolic disorders. While the benefits of physical exercise on type 2 diabetes and prevention and control is well conceived, recent studies imply that such beneficial metabolic changes can occur through epigenetic alterations like histone modifications [52]. Exercise benefits at the molecular level are linked, in part, to transcriptional activation myocyte-specific enhancer factor (MEF) 2A in coordination with PPAR- $\gamma$, PPARGC1a, and acetylation of GLUT4 in the skeletal muscle [53]. It has been recently shown that exercise increases the binding of MEF2A to the Cpt1b promoter in the mouse skeletal muscle and this requires repression of MEF2A-binding partners such as HDAC5 and HDAC3 [54]. Interestingly, a short-term intensive practice of mindfulness meditation has been demonstrated to rapidly decrease histone deacetylases (more strikingly HDAC3) and inflammatory gene 
Table 2 Pearson correlation analysis of HDAC3 activity/HDAC3 mRNA expression with biochemical and molecular parameters in the study groups

\begin{tabular}{|c|c|c|c|c|}
\hline \multirow[t]{2}{*}{ Variables } & \multicolumn{2}{|c|}{ HDAC3 activity } & \multicolumn{2}{|c|}{ HDAC3 mRNA } \\
\hline & $r$ value & $p$ value & $r$ value & $p$ value \\
\hline Age (years) & -0.144 & 0.318 & 0.066 & 0.739 \\
\hline $\mathrm{BMI}\left(\mathrm{kg} / \mathrm{m}^{2}\right)$ & 0.208 & 0.147 & 0.218 & 0.265 \\
\hline Waist (cm) & 0.028 & 0.865 & 0.121 & 0.602 \\
\hline Systolic blood pressure $(\mathrm{mmHg})$ & 0.098 & 0.498 & 0.233 & 0.233 \\
\hline Diastolic blood pressure $(\mathrm{mmHg})$ & -0.015 & 0.916 & 0.199 & 0.31 \\
\hline Fasting plasma glucose (mg/dL) & 0.611 & $<0.001$ & 0.602 & 0.001 \\
\hline $\mathrm{HbA1c}(\%)$ & 0.474 & 0.001 & 0.447 & 0.017 \\
\hline HOMA-IR & 0.526 & $<0.001$ & 0.378 & 0.047 \\
\hline Plasma TNF-a & 0.534 & $<0.001$ & 0.417 & 0.027 \\
\hline Plasma IL-6 & 0.617 & $<0.001$ & 0.381 & 0.045 \\
\hline Serum cholesterol (mg/dl) & -0.181 & 0.210 & 0.044 & 0.825 \\
\hline Serum triglycerides $(\mathrm{mg} / \mathrm{dl})$ & 0.106 & 0.465 & 0.152 & 0.439 \\
\hline LDL cholesterol (mg/dl) & -0.19 & 0.185 & 0.023 & 0.908 \\
\hline HDL cholesterol (mg/dl) & -0.161 & 0.263 & -0.052 & 0.792 \\
\hline TNF-a mRNA expression & 0.175 & 0.374 & 0.027 & 0.892 \\
\hline IL-6 mRNA expression & 0.167 & 0.395 & -0.016 & 0.935 \\
\hline NFkB mRNA expression & 0.627 & $<0.001$ & 0.118 & 0.559 \\
\hline IL1- $\beta$ mRNA expression & 0.643 & 0.001 & 0.247 & 0.255 \\
\hline MCP-1 mRNA expression & 0.521 & 0.004 & 0.846 & $<0.001$ \\
\hline SOCS3 mRNA expression & 0.708 & $<0.001$ & 0.557 & 0.002 \\
\hline TLR2 mRNA expression & 0.484 & 0.009 & 0.156 & 0.437 \\
\hline TLR4 mRNA expression & 0.444 & 0.018 & 0.234 & 0.240 \\
\hline DBC1 mRNA expression & -0.396 & 0.037 & -0.315 & 0.109 \\
\hline HDAC3 mRNA expression & 0.549 & 0.002 & - & - \\
\hline HDAC3 activity & - & - & 0.549 & 0.002 \\
\hline Sirt1 mRNA expression & -0.414 & 0.029 & -0.125 & 0.527 \\
\hline
\end{tabular}

Italic values are to indicate the statistical significance

expression [55] implying that appropriate lifestyle modifications may offer metabolic benefits operating through epigenetic mechanisms.

\section{Conclusions}

To conclude, in a relevant clinical diabetes setting, we have demonstrated increased HDAC3 activity/ HDAC3 mRNA levels in patients with type 2 diabetes that was positively correlated to all the inflammatory markers profiled, poor glycemic control, and insulin resistance. The striking message from our study is that while looking for antidiabetic drugs with newer mode of action as well as additional antiinflammatory benefits, the development of selective isoform-specific $H D A C 3$ inhibitors (with appropriate pharmacokinetics and dynamics) appear to have potential advantage.

\section{Abbreviations}

BMI: Body mass index; DBC-1: Deleted in breast cancer 1; HDAC: Histone deacetylase; HDAC3: Histone deacetylase 3; HOMA-IR: Homeostatic model assessment; IL-1ß: Interleukin-1B; IL-6: Interleukin-6; MCP-1: Monocyte chemoattractant protein 1; NFkB: Nuclear factor kappa-B; NGT: Normal glucose tolerance; PBMC: Peripheral blood mononuclear cell; Sirt1: Sirtuin1; SOCS-3: Suppressor of cytokine signaling 3; T2DM: Type 2 diabetes mellitus; TLR2: Toll-like receptor 2; TLR4: Toll-like receptor 4; TNF-a: Tumor necrosis factor-a

\section{Acknowledgements}

Authors acknowledge the grant support from the Department of Biotechnology (DBT), Govt. of India, and the seed money grant from MDRF Intramural Research Funding (MIRF). C.S acknowledges the Council of Scientific and Industrial Research (CSIR), New Delhi, India, for his financial assistance (Senior Research Fellowship).

\section{Funding}

This work was supported by grants from the Department of Biotechnology (DBT), Govt. of India; MDRF Intramural Research Funding (MIRF); and research fellowship assistance from the Council of Scientific \& Industrial Research (CSIR), New Delhi, India.

\section{Availability of data and materials}

Authors consent to the availability of data and materials.

\section{Authors' contributions}

MB conceived, designed, supervised, and commented on all drafts of this paper. CS, PP, BM, RL, and DP conducted the overall experiments, participated in the data collection, analysis, and molecular investigations, and helped in the drafts. RMA and VM assisted the subjects' recruitment and clinical characterization. VM and $\mathrm{MB}$ contributed to the data interpretation and manuscript completion. All authors read and approved the final manuscript.

\section{Competing interests}

The authors declare that they have no competing interests.

\section{Consent for publication}

All the authors approved the manuscript and consented for publication.

\section{Ethics approval and consent to participate}

The study has been carried out in accordance with the guidelines of Declaration of Helsinki and was approved by the Institutional Ethics Committee of the Madras Diabetes Research Foundation, and informed written consent has been obtained from all the study subjects.

Received: 29 May 2016 Accepted: 15 November 2016

Published online: 24 November 2016

\section{References}

1. International Diabetes Federation. IDF diabetes atlas. 7th ed. Brussels: International Diabetes Federation; 2015.

2. Mohan V, Venkatraman JV, Pradeepa R. Epidemiology of cardiovascular disease in type 2 diabetes: the Indian scenario. J Diabetes Sci Technol. 2010; 4:158-70.

3. Unnikrishnan R, Anjana RM, Mohan V. Diabetes in South Asians: is the phenotype different? Diabetes. 2014;63:53-5.

4. Streja D, Cressey P, Rabkin SW. Associations between inflammatory markers, traditional risk factors, and complications in patients with type 2 diabetes mellitus. J Diabetes Complicat. 2003;17:120-7.

5. Shoelson SE, Lee J, Goldfine AB. Inflammation and insulin resistance. J Clin Invest. 2006;116:1793-801.

6. Asegaonkar SB, Marathe A, Tekade ML, Cherekar L, Bavikar J, Bardapurkar J, Ajay R. High-sensitivity C-reactive protein: a novel cardiovascular risk predictor in type 2 diabetics with normal lipid profile. J Diabetes Complicat. 2011;25:368-70

7. Balasubramanyam M, Aravind S, Gokulakrishnan K, Prabu P, Sathishkumar C Ranjani H, Mohan V. Impaired miR-146a expression links subclinical inflammation and insulin resistance in type 2 diabetes. Mol Cell Biochem. 2011;351:197-205 
8. Lenin R, Sankaramoorthy A, Mohan V, Balasubramanyam M. Altered immunometabolism at the interface of increased endoplasmic reticulum (ER) stress in patients with type 2 diabetes. J Leukoc Biol. 2015;98:615-22.

9. Ling C, Groop L. Epigenetics: a molecular link between environmental factors and type 2 diabetes. Diabetes. 2009;58:2718-25.

10. Wegner M, Neddermann D, Piorunska-Stolzmann M, Jagodzinski PP. Role of epigenetic mechanisms in the development of chronic complications of diabetes. Diabetes Res Clin Pract. 2014;105:164-75.

11. Tang J, Yan H, Zhuang S. Histone deacetylases as targets for treatment of multiple diseases. Clin Sci (Lond). 2013;124:651-62.

12. Christensen DP, Dahllöf M, Lundh M, Rasmussen DN, Nielsen MD, Billestrup N, Grunnet LG, Mandrup-Poulsen T. Histone deacetylase (HDAC) inhibition as a novel treatment for diabetes mellitus. Mol Med (Cambridge, Mass). 2011;17:378-90.

13. Galmozzi A, Mitro N, Ferrari A, Gers E, Gilardi F, Godio C, Cermenati G, Gualerzi A, Donetti E, Rotili D, et al. Inhibition of class I histone deacetylases unveils a mitochondrial signature and enhances oxidative metabolism in skeletal muscle and adipose tissue. Diabetes. 2013;62:732-42.

14. Plaisance V, Rolland L, Gmyr V, Annicotte J-SS, Kerr-Conte J, Pattou F, Abderrahmani A. The class I histone deacetylase inhibitor MS-275 prevents pancreatic beta cell death induced by palmitate. J Diabetes Res. 2014;2014:195739.

15. Milne JC, Lambert PD, Schenk S, Carney DP, Smith JJ, Gagne DJ, Jin L, Boss O, Perni RB, Vu CB, et al. Small molecule activators of SIRT1 as therapeutics for the treatment of type 2 diabetes. Nature. 2007:450:712-6.

16. Friedewald WT, Levy RI, Fredrickson DS. Estimation of the concentration of low-density lipoprotein cholesterol in plasma, without use of the preparative ultracentrifuge. Clin Chem. 1972;18(6):499-502.

17. Ye J. Improving insulin sensitivity with HDAC inhibitor. Diabetes. 2013; 62:685-7.

18. Larsen L, Tonnesen M, Ronn SG, Størling J, Jørgensen S, Mascagni P, Dinarello CA, Billestrup N, Mandrup-Poulsen T. Inhibition of histone deacetylases prevents cytokine-induced toxicity in beta cells. Diabetologia. 2007;50:779-89.

19. Lundh M, Christensen DP, Damgaard Nielsen M, Richardson SJ, Dahllöf MS Skovgaard T, Berthelsen J, Dinarello CA, Stevenazzi A, Mascagni P, et al. Histone deacetylases 1 and 3 but not 2 mediate cytokine-induced beta cell apoptosis in INS-1 cells and dispersed primary islets from rats and are differentially regulated in the islets of type 1 diabetic children. Diabetologia. 2012:55:2421-31.

20. Jeong Y, Du R, Zhu X, Yin S, Wang J, Cui H, Cao W, Lowenstein CJ. Histone deacetylase isoforms regulate innate immune responses by deacetylating mitogen-activated protein kinase phosphatase-1. J Leukoc Biol. 2014;95:651-9.

21. Dje N'Guessan P, Riediger F, Vardarova K, Scharf S, Eitel J, Opitz B, Slevogt H, Weichert W, Hocke AC, Schmeck B, et al. Statins control oxidized LDLmediated histone modifications and gene expression in cultured human endothelial cells. Arterioscler Thromb Vasc Biol. 2009:29:380-6.

22. Balasubramanyam M, Premanand C, Mohan V. The lymphocyte as a cellular model to study insights into the pathophysiology of diabetes and its complications. Ann NY Acad Sci. 2002;958:399-402.

23. Meier BC, Wagner BK. Inhibition of HDAC3 as a strategy for developing novel diabetes therapeutics. Epigenomics. 2014;6:209-14.

24. Chen X, Barozzi I, Termanini A, Prosperini E, Recchiuti A, Dalli J, Mietton F, Matteoli G, Hiebert S, Natoli G. Requirement for the histone deacetylase Hdac3 for the inflammatory gene expression program in macrophages. Proc Natl Acad Sci U S A. 2012;109:74.

25. Li D, Wang X, Ren W, Ren J, Lan X, Wang F, Li H, Zhang F, Han Y, Song T, et al. High expression of liver histone deacetylase 3 contributes to high-fatdiet-induced metabolic syndrome by suppressing the PPAR- $\gamma$ and LXR- $a-$ pathways in E3 rats. Mol Cell Endocrinol. 2011;344:69-80.

26. McGee-Lawrence ME, White TA, LeBrasseur NK, Westendorf JJ. Conditional deletion of Hdac3 in osteoprogenitor cells attenuates diet-induced systemic metabolic dysfunction. Mol Cell Endocrinol. 2015;410:42-51.

27. Hoeksema MA, Gijbels MJ, Van den Bossche J, van der Velden S, Sijm A, Neele AE, Seijkens T, Stöger JL, Meiler S, Boshuizen MC, et al. Targeting macrophage histone deacetylase 3 stabilizes atherosclerotic lesions. EMBO Mol Med. 2014;6:1124-32.

28. Zeng Z, Liao R, Yao Z, Zhou W, Ye P, Zheng X, Li X, Huang Y, Chen S, Chen $Q$. Three single nucleotide variants of the HDAC gene are associated with type 2 diabetes mellitus in a Chinese population: a community-based casecontrol study. Gene. 2014;533:427-33.
29. Lundh M, Galbo T, Poulsen SS, Mandrup-Poulsen T. Histone deacetylase 3 inhibition improves glycaemia and insulin secretion in obese diabetic rats. Diabetes Obes Metab. 2015;17:703-7.

30. Jia H, Morris CD, Williams RM, Loring JF, Thomas EA. HDAC inhibition imparts beneficial transgenerational effects in Huntington's disease mice via altered DNA and histone methylation. Proc Natl Acad Sci U S A. 2015;112:64

31. Kim Y, Kim K, Park D, Lee E, Lee H, Lee Y-SS, Choe J, Jeoung D. Histone deacetylase 3 mediates allergic skin inflammation by regulating expression of MCP1 protein. J Biol Chem. 2012;287:25844-59.

32. Kotas ME, Gorecki MC, Gillum MP. Sirtuin-1 is a nutrient-dependent modulator of inflammation. Adipocyte. 2013;2:113-8.

33. Song YS, Lee SK, Jang YJ, Park HS, Kim J-HH, Lee YJ, Heo Y-SS. Association between low SIRT1 expression in visceral and subcutaneous adipose tissues and metabolic abnormalities in women with obesity and type 2 diabetes. Diabetes Res Clin Pract. 2013;101:341-8

34. Yoshizaki T, Milne JC, Imamura T, Schenk S, Sonoda N, Babendure JL, Lu J-CC, Smith JJ, Jirousek MR, Olefsky JM. SIRT1 exerts antiinflammatory effects and improves insulin sensitivity in adipocytes. Mol Cell Biol. 2009;29:1363-74.

35. Picard F, Kurtev M, Chung N, Topark-Ngarm A, Senawong T, Machado De Oliveira R, Leid M, McBurney MW, Guarente L. Sirt1 promotes fat mobilization in white adipocytes by repressing PPAR-gamma. Nature. 2004; 429:771-6.

36. de Kreutzenberg SV, Ceolotto G, Papparella I, Bortoluzzi A, Semplicini A Dalla Man C, Cobelli C, Fadini GP, Avogaro A. Downregulation of the longevity-associated protein sirtuin 1 in insulin resistance and metabolic syndrome: potential biochemical mechanisms. Diabetes. 2010;59:1006-15.

37. Gillum MP, Kotas ME, Erion DM, Kursawe R, Chatterjee P, Nead KT, Muise ES, Hsiao JJ, Frederick DW, Yonemitsu S, et al. SirT1 regulates adipose tissue inflammation. Diabetes. 2011;60:3235-45.

38. Chini CC, Escande C, Nin V, Chini EN. HDAC3 is negatively regulated by the nuclear protein DBC1. J Biol Chem. 2010;285:40830-7.

39. Nin V, Chini CC, Escande C, Capellini V, Chini EN. Deleted in breast cancer 1 (DBC1) protein regulates hepatic gluconeogenesis. J Biol Chem. 2014;289:5518-27.

40. Ma Y-DD, Fang J, Liu H, Zhou L. Increased HDAC3 and decreased miRNA130a expression in PBMCs through recruitment HDAC3 in patients with spinal cord injuries. Int J Clin Exp Pathol. 2015;8:1682-9.

41. Wang JH, Shih KS, Wu YW, Wang AW, Yang CR. Histone deacetylase inhibitors increase microRNA-146a expression and enhance negative regulation of interleukin-1 $\beta$ signaling in osteoarthritis fibroblast-like synoviocytes. Osteoarthritis Cartilage. 2013;21:1987-96.

42. Miller SJ. Cellular and physiological effects of short-chain fatty acids. Mini Rev Med Chem. 2004:4:839-45.

43. Waldecker M, Kautenburger T, Daumann H, Busch C, Schrenk D. Inhibition of histone-deacetylase activity by short-chain fatty acids and some polyphenol metabolites formed in the colon. J Nutr Biochem. 2008;19:587-93.

44. Steliou K, Boosalis MS, Perrine SP, Sangerman J, Faller DV. Butyrate histone deacetylase inhibitors. BioResearch Open Access. 2012;1:192-8.

45. Jakobsdottir G, Xu J, Molin G, Ahrné S, Nyman M. High-fat diet reduces the formation of butyrate, but increases succinate, inflammation, liver fat and cholesterol in rats, while dietary fibre counteracts these effects. PloS One. 2013; 8(11):e80476

46. Mattace Raso G, Simeoli R, Russo R, lacono A, Santoro A, Paciello O, Ferrante MC, Canani RB, Calignano A, Meli R. Effects of sodium butyrate and its synthetic amide derivative on liver inflammation and glucose tolerance in an animal model of steatosis induced by high fat diet. PloS One. 2013; 8(7):e68626.

47. Khan S, Jena GB. Protective role of sodium butyrate, a HDAC inhibitor on beta-cell proliferation, function and glucose homeostasis through modulation of p38/ERK MAPK and apoptotic pathways: study in juvenile diabetic rat. Chem Biol Interact. 2014;213:1-12.

48. Chang PV, Hao L, Offermanns S, Medzhitov R. The microbial metabolite butyrate regulates intestinal macrophage function via histone deacetylase inhibition. Proc Natl Acad Sci U S A. 2014;111:2247-52.

49. Qin J, Li Y, Cai Z, Li S, Zhu J, Zhang F, Liang S, Zhang W, Guan Y, Shen D, et al. A metagenome-wide association study of gut microbiota in type 2 diabetes. Nature. 2012:490:55-60,

50. Remely M, Aumueller E, Merold C, Dworzak S, Hippe B, Zanner J, Pointner A, Brath $\mathrm{H}$, Haslberger AG. Effects of short chain fatty acid producing bacteria 
on epigenetic regulation of FFAR3 in type 2 diabetes and obesity. Gene. 2014;537:85-92

51. Hartstra AV, Bouter KE, Bäckhed F, Nieuwdorp M. Insights into the role of the microbiome in obesity and type 2 diabetes. Diabetes Care. 2015;38:159-65.

52. Ntanasis-Stathopoulos J, Tzanninis JG, Philippou A, Koutsilieris M. Epigenetic regulation on gene expression induced by physical exercise. J Musculoskelet Neuronal Interact. 2013;13:133-46.

53. McGee SL, Hargreaves M. Exercise and skeletal muscle glucose transporter 4 expression: molecular mechanisms. Clin Exp Pharmacol Physiol. 2006:33:395-9.

54. Yuan H, Niu Y, Liu X, Fu L. Exercise increases the binding of MEF2A to the Cpt1b promoter in mouse skeletal muscle. Acta Physiol (Oxf). 2014;212:283-92.

55. Kaliman P, Alvarez-López MJJ, Cosín-Tomás M, Rosenkranz MA, Lutz A, Davidson RJ. Rapid changes in histone deacetylases and inflammatory gene expression in expert meditators. Psychoneuroendocrinology. 2014;40:96-107.

Submit your next manuscript to BioMed Central and we will help you at every step:

- We accept pre-submission inquiries

- Our selector tool helps you to find the most relevant journal

- We provide round the clock customer support

- Convenient online submission

- Thorough peer review

- Inclusion in PubMed and all major indexing services

- Maximum visibility for your research

Submit your manuscript at www.biomedcentral.com/submit
Biomed Central 